\title{
COEXISTENCE OF ASTHMATIC AND NON-RESPIRATORY ALLERGIC SYMPTOMS IN CHILDREN OF BATUMI REGION, GEORGIA: OCCURRENCE AND ASSOCIATION WITH KNOWN DIAGNOSIS OF ASTHMA
}

\author{
Vakhtang Beridze ${ }^{1}$, Tamar Bakhtadze ${ }^{1}$, Sophio Beridze ${ }^{1}$, Karaman Phagava², Ivane Chkhaidze ${ }^{3}$, Grzegorz Marek \\ Brożek $^{4}$, Jan Eugeniusz Zejda ${ }^{4}$ \\ ${ }^{1}$ M. lashvili Batumi Maternity and Child Central Hospital, Shota Rustaveli State University, Batumi, Georgia \\ ${ }^{2}$ Department of Paediatrics, Tbilisi State Medical University, Tbilisi, Georgia \\ ${ }^{3}$ Tbilisi State Medical University, Tbilisi, Georgia \\ ${ }^{4}$ Department of Epidemiology, Faculty of Medical Sciences, Medical University of Silesia in Katowice, Katowice, Poland
}

\section{SUMMARY}

Objectives: Our recent studies showed that in children in the Batumi region, Georgia, underdiagnosis of asthma is $65 \%$, and that not all children with known asthma had a history of allergic disorders. So, we decided to assess the association of known diagnosis of paediatric asthma with asthma-like symptoms and non-respiratory allergic symptoms and diseases using questionnaire-derived data provided by respiratory health survey.

Methods: Subjects of the cross-sectional population-based study were 3,239 urban and 2,113 rural children aged 5-17 years whose respiratory status was assessed using the International Study of Asthma and Allergies in Childhood (ISAAC) questionnaire. For children with a known diagnosis of asthma, the occurrence of respiratory symptoms suggestive of asthmatic tendency and of allergic symptoms and diseases was measured and statistical association of known asthma with the respiratory and allergic symptoms was expressed as odds ratios (OR) and their $95 \%$ confidence intervals $(95 \% \mathrm{Cl})$.

Results: Respiratory and all allergic symptoms and diseases, except for eczema, were statistically significantly $(p<0.05)$ more prevalent in children with asthma than in children without asthma. Based on the distribution of asthma vis-à-vis asthmatic tendency without or with allergic symptoms and allergic diseases the following odds ratios expressing likelihood of asthma were obtained: for asthmatic tendency: OR=18.09 (95\% Cl: 11.82-27.68), for any allergic symptom: $\mathrm{OR}=6.85$ (95\% Cl: $4.69-10.02)$, for any allergic disease: $\mathrm{OR}=10.75$ (95\% Cl: $7.36-15.70)$, for asthmatic tendency with coexisting any allergic symptom: $\mathrm{OR}=18.94(95 \% \mathrm{Cl}: 12.96-27.68)$, for asthmatic tendency with coexisting any allergic disease: $\mathrm{OR}=25.65$ (95\% Cl: 17.47-37.67), and for asthmatic tendency with coexisting any allergic symptom and allergic disease: $\mathrm{OR}=27.02$ (95\% Cl: 18.18-40.15).

Conclusions: The findings support the view that in epidemiological setting questionnaire-based studies on asthma seems to more readily identify cases in children with more severe clinical presentation of the disease and with coexisting allergic disorders, perhaps reflecting diagnostic practices of consulting paediatricians.

Key words: asthma, allergy, children, underdiagnosis, Georgia

Address for correspondence: G. Brożek, Medical University of Silesia, Department of Epidemiology, Medykow 18 Str, 40-752 Katowice, Poland. E-mail: gbrozek@sum.edu.pl

https://doi.org/10.21101/cejph.a6143

\section{INTRODUCTION}

Underdiagnosis and overdiagnosis of paediatric asthma is a well described phenomenon in a number of populations (1). However, an infrequent occurrence of paediatric asthma provided by epidemiological studies performed in the countries of Central and Eastern Europe suggests that in that region underdiagnosis and not overdiagnosis of paediatric asthma is a real problem (2). Our large population-based respiratory health survey including 5,351 early-school children in the region of Batumi, Georgia, showed that physician-diagnosed asthma was reported by parents of $2.2 \%$ of children (3). The follow-up project based on the survey involved clinical examination of 437 participants who had a history of asthma-like symptoms and no diagnosis of asthma. Detailed methodology of mentioned research is described in the article by Zejda et al. 2019 (4). Its results revealed 107 cases of undiagnosed asthma suggesting that $65 \%$ of paediatric asthma cases were undiagnosed (4). Such a finding may reflect a number of factors including socioeconomic factors, restricted access to specialized diagnostic facilities, so called labelling effect or vary- 
ing diagnostic criteria between consulting physicians (1,5-7). On the other hand, underdiagnosis of paediatric asthma may be related to the intricacies of a natural history of the disease. Our findings showed that children with undiagnosed asthma had less history of allergic disorders compared to children with diagnosed asthma and other evidence supports that view $(4,8)$. Intensity of respiratory symptoms and coexisting allergic disorders may play an important role and may affect the results of questionnaire-based detection of physician diagnosed paediatric asthma. Given that assumption we decided to assess the association of known diagnosis of paediatric asthma with asthma-like symptoms and non-respiratory allergic symptoms and diseases using questionnaire-derived data provided by respiratory health survey.

\section{MATERIALS AND METHODS}

The details regarding the study protocol are described in our earlier article (3). The subjects were 3,239 urban and 2,113 rural children residing in the Batumi region (Adjara, Georgia) participating in a population-based respiratory health survey (participation rate in urban area was $91.2 \%$ and in rural area $73.8 \%$ ). The study tool was a respiratory health questionnaire that included questions from the International Study of Asthma and Allergies in Childhood (ISAAC) Reference.

Asthmatic tendency was defined by the presence of one or more of the following respiratory symptoms not associated with infection in a child and reported by parents in a questionnaire: episodes of dry cough at night, attacks of shortness of breath, chest congestion with productive cough, wheeze at rest, wheeze during or after exercise. Paediatric asthma was defined by the positive answer to the question in the questionnaire: "Has a doctor ever diagnosed asthma in this child?"

Allergic disorders were defined by the positive answers to the questions on such symptoms as sneezing or runny nose, itchy/ watery eyes, recurrent itchy rash, and physician diagnoses of hay fever, eczema or a general diagnosis of allergy.

Statistical analysis was done using SAS 15.2 software and involved description of the distributions of quantitative variables in terms of arithmetic mean and standard deviation and of qualitative variables in terms of absolute and relative frequencies. Differences in the distributions of quantitative variables were assessed using the Kruskal-Wallis test and in the distributions of qualitative variables by the $\chi^{2}$ test. Inference regarding statistical significance was based on the criterion $p<0.05$. The magnitude of the statistical association of diagnosed asthma with respiratory symptoms and allergic disorders was assessed by calculation of odds ratios and their $95 \%$ confidence intervals (OR, 95\% CI).

\section{RESULTS}

The study group included 3,239 urban and 2,113 rural children who differed statistically significantly $(\mathrm{p}<0.001)$ in terms of age distribution $(9.5 \pm 2.4$ years and $11.0 \pm 2.1$ years, respectively). The frequency of boys was similar in urban and rural children (46.9\% and $47.0 \%$, respectively; $p=0.9$ ). Table 1 shows the prevalence of asthma-like symptoms and of allergic symptoms and diseases in urban and rural children. Frequency of allergic symptoms and diseases diagnosed in the past was similar in urban and rural children except for eczema that was reported by small numbers of children in both regions. All asthma-like symptoms, except for chest congestion, were statistically significantly more prevalent in rural than in urban children.

The frequency of allergic symptoms and diseases in children with asthmatic tendency and in children without that diagnosis are shown in Table 2. All allergic disorders were statistically significantly more prevalent in children with asthmatic tendency both in urban and in rural setting.

Table 1. Prevalence of asthma-like symptoms and allergic symptoms and allergic diseases in urban and rural children (N=5,352)

\begin{tabular}{|l|c|c|c|c|}
\hline Symptom/disease & $\begin{array}{c}\text { All children } \\
\text { Total 5,352 } \\
\mathbf{n}(\%)\end{array}$ & $\begin{array}{c}\text { Urban children } \\
\text { Total 3,239 } \\
\mathbf{n}(\%)\end{array}$ & $\begin{array}{c}\text { Rural children } \\
\text { Total 2,113 } \\
\mathbf{n}(\%)\end{array}$ & $\mathbf{p}^{\text {-value }}$ \\
\hline Dry cough & $547(10.2)$ & $268(8.2)$ & $279(13.2)$ & $<0.001$ \\
\hline Shortness of breath & $181(3.3)$ & $80(2.4)$ & $101(4.7)$ & $<0.001$ \\
\hline Chest congestion & $319(5.9)$ & $188(5.8)$ & $131(6.2)$ & 0.5 \\
\hline Chest wheeze at rest & $160(3.1)$ & $80(2.4)$ & $60(4.2)$ & 0.0004 \\
\hline Chest wheeze at exercise & $137(2.5)$ & $71(2.1)$ & $410(19.4)$ & 0.03 \\
\hline Asthmatic tendency & $856(16.0)$ & $446(13.7)$ & $60(2.8)$ & $<0.001$ \\
\hline Asthma ever diagnosed & $119(2.2)$ & $59(1.8)$ & $322(15.2)$ & 0.01 \\
\hline Sneezing or runny nose & $801(14.9)$ & $479(14.7)$ & $166(7.8)$ & 0.6 \\
\hline Itchy/watery eyes & $417(7.7)$ & $251(7.7)$ & $164(7.7)$ & 0.8 \\
\hline Recurrent itchy rash & $375(7.0)$ & $211(6.5)$ & $124(5.8)$ & 0.08 \\
\hline Hay fever & $279(5.2)$ & $155(4.7)$ & $33(1.5)$ & 0.08 \\
\hline Eczema & $47(0.8)$ & $14(0.4)$ & $233(11.0)$ & $<0.001$ \\
\hline Allergy & $648(12.1)$ & $415(12.8)$ & 0.05 \\
\hline
\end{tabular}

*Statistical significance of the difference between urban and rural children - result of $X^{2}$ test 
Table 2. Prevalence of allergic symptoms and allergic diseases in urban and rural children according to diagnosis of asthmatic tendency

\begin{tabular}{|c|c|c|c|c|c|c|c|c|c|}
\hline \multicolumn{10}{|c|}{ Allergic symptoms } \\
\hline \multirow{2}{*}{$\mathrm{AT}^{*}$} & \multicolumn{3}{|c|}{$\begin{array}{l}\text { Sneezing or runny nose } \\
\mathrm{n}(\%)\end{array}$} & \multicolumn{3}{|c|}{$\begin{array}{c}\text { Itchy-watery eyes } \\
n(\%)\end{array}$} & \multicolumn{3}{|c|}{$\begin{array}{c}\text { Recurrent itchy rash } \\
\mathrm{n}(\%)\end{array}$} \\
\hline & Urban & Rural & Total & Urban & Rural & Total & Urban & Rural & Total \\
\hline $\begin{array}{l}\text { ATt } \\
N=856\end{array}$ & $165(34.4)$ & $155(37.8)$ & $320(37.3)$ & $108(24.2)$ & $96(23.4)$ & $204(23.8)$ & $66(14.8)$ & $68(16.5)$ & $134(15.6)$ \\
\hline $\begin{array}{l}\text { AT- } \\
N=4,496\end{array}$ & $314(11.2)$ & $167(9.8)$ & $481(10.7)$ & $143(5.1)$ & $70(4.1)$ & $213(4.7)$ & $145(5.2)$ & $96(5.6)$ & $241(5.3)$ \\
\hline$p$-value ${ }^{* *}$ & $<0.001$ & $<0.001$ & $<0.001$ & $<0.001$ & $<0.001$ & $<0.001$ & $<0.001$ & $<0.001$ & $<0.001$ \\
\hline \multicolumn{10}{|c|}{ Allergic diseases } \\
\hline \multirow[t]{2}{*}{$\mathrm{AT}^{*}$} & \multicolumn{3}{|c|}{$\begin{array}{c}\text { Hay fever } \\
\mathrm{n}(\%)\end{array}$} & \multicolumn{3}{|c|}{$\begin{array}{c}\text { Eczema } \\
\mathrm{n}(\%)\end{array}$} & \multicolumn{3}{|c|}{$\begin{array}{c}\text { Allergy } \\
\mathrm{n}(\%)\end{array}$} \\
\hline & Urban & Rural & Total & Urban & Rural & Total & Urban & Rural & Total \\
\hline $\begin{array}{l}\text { AT+ } \\
N=856\end{array}$ & $59(13.2)$ & $71(17.3)$ & $130(15.2)$ & $7(1.5)$ & $13(3.1)$ & $20(2.3)$ & $137(30.7)$ & $117(28.5)$ & $254(29.6)$ \\
\hline $\begin{array}{l}\text { AT- } \\
N=4,496\end{array}$ & $96(3.4)$ & $53(3.1)$ & $149(3.3)$ & $7(0.2)$ & $20(1.1)$ & $27(0.6)$ & $278(9.9)$ & $116(6.8)$ & $394(8.7)$ \\
\hline$p$-value & $<0.001$ & $<0.001$ & $<0.001$ & 0.001 & 0.003 & $<0.001$ & $<0.001$ & $<0.001$ & $<0.001$ \\
\hline
\end{tabular}

${ }^{*}$ Asthmatic tendency present (AT+) or absent (AT-); ** result of $\chi^{2}$ test

Asthma ever diagnosed in a child was reported by parents of 119 children $(2.2 \%)$ and it was more prevalent $(\mathrm{p}=0.01)$ in rural $(2.8 \%)$ than in urban children $(1.8 \%)$ but its frequency was similar in boys and girls $(2.0 \%$ and $2.4 \%$, respectively, $\mathrm{p}=0.3)$. Table 3 shows the occurrence of asthma-like symptoms and allergic disorders in children with and without diagnosis of asthma. Except for eczema all allergic symptoms and diseases were statistically significantly more prevalent in children with asthma than in children without asthma, both in urban and in rural setting.

In the examined group of 5,352 children the frequency of asthmatic tendency was $16.0 \%$, any allergic symptom $21.4 \%$, and any allergic disease $12.1 \%$. The frequency of asthma in children with asthmatic tendency was $10.5 \%$, in children with any allergic symptom $6.6 \%$, and in children with any allergic disease $9.6 \%$.

Table 3. Prevalence of allergic symptoms and allergic diseases in urban and rural children according to diagnosis of paediatric asthma

\begin{tabular}{|c|c|c|c|c|c|c|c|c|c|}
\hline \multicolumn{10}{|c|}{ Allergic symptoms } \\
\hline \multirow{2}{*}{$A^{*}$} & \multicolumn{3}{|c|}{$\begin{array}{c}\text { Sneezing or runny nose } \\
\mathrm{n}(\%)\end{array}$} & \multicolumn{3}{|c|}{$\begin{array}{c}\text { Itchy-watery eyes } \\
n(\%)\end{array}$} & \multicolumn{3}{|c|}{$\begin{array}{c}\text { Recurrent itchy rash } \\
\mathrm{n}(\%)\end{array}$} \\
\hline & Urban & Rural & Total & Urban & Rural & Total & Urban & Rural & Total \\
\hline $\begin{array}{l}A^{+} \\
N=119\end{array}$ & $32(54.2)$ & $34(56.6)$ & $66(55.4)$ & $24(40.6)$ & $23(38.3)$ & $47(39.5)$ & $12(20.3)$ & $16(26.6)$ & $28(23.5)$ \\
\hline $\begin{array}{l}A- \\
N=5,233\end{array}$ & $447(14.0)$ & $288(14.0)$ & $735(14.0)$ & $227(7.1)$ & $143(6.9)$ & $370(7.0)$ & $199(6.2)$ & $148(7.2)$ & $347(6.6)$ \\
\hline$p$-value ${ }^{* \star}$ & $<0.001$ & $<0.001$ & $<0.001$ & $<0.001$ & $<0.001$ & $<0.001$ & $<0.001$ & $<0.001$ & $<0.001$ \\
\hline \multicolumn{10}{|c|}{ Allergic Diseases } \\
\hline \multirow[t]{2}{*}{$A^{*}$} & \multicolumn{3}{|c|}{$\begin{array}{c}\text { Hay fever } \\
\mathrm{n}(\%)\end{array}$} & \multicolumn{3}{|c|}{$\begin{array}{c}\text { Eczema } \\
\mathrm{n}(\%)\end{array}$} & \multicolumn{3}{|c|}{$\begin{array}{c}\text { Allergy } \\
\mathrm{n}(\%)\end{array}$} \\
\hline & Urban & Rural & Total & Urban & Rural & Total & Urban & Rural & Total \\
\hline $\begin{array}{l}A^{+} \\
N=119\end{array}$ & $22(37.2)$ & $17(28.3)$ & $39(32.7)$ & $1(1.6)$ & $1(1.6)$ & $2(1.7)$ & $38(64.4)$ & $34(56.6)$ & $72(60.5)$ \\
\hline $\begin{array}{l}A- \\
N=5,233\end{array}$ & $133(4.1)$ & $107(5.2)$ & $240(4.5)$ & $13(0.4)$ & $32(1.5)$ & $45(0.8)$ & $377(11.8)$ & $199(9.6)$ & $576(11.0)$ \\
\hline$p$-value & $<0.001$ & $<0.001$ & $<0.001$ & 0.1 & 0.9 & 0.3 & $<0.001$ & $<0.001$ & $<0.001$ \\
\hline
\end{tabular}


In children who had asthmatic tendency and at least one allergic symptom the frequency of asthma was $16.5 \%$. In children with coexisting asthmatic tendency with any allergic disease the frequency of asthma was $22.0 \%$. In the subgroup of children who met three analysed conditions (asthmatic tendency and any allergic symptom and any allergic disease) the frequency of asthma was $26.0 \%$. Based on the distribution of asthma vis-à-vis asthmatic tendency without or with allergic symptom and allergic disease the following odds ratios expressing likelihood of asthma were obtained: for asthmatic tendency $\mathrm{OR}=18.09$ (95\% CI: 11.82-27.68), for any allergic symptom $\mathrm{OR}=6.85$ (95\% CI: 4.69-10.02), for any allergic disease $\mathrm{OR}=10.75$ (95\% CI: 7.36-15.70), for asthmatic tendency with coexisting any allergic symptom $\mathrm{OR}=18.94$ (95\% CI: 12.96-27.68), for asthmatic tendency with coexisting any allergic disease $\mathrm{OR}=25.65$ (95\% CI: 17.47-37.67), and for asthmatic tendency with coexisting any allergic symptom and allergic disease $\mathrm{OR}=27.02$ (95\% CI: 18.18-40.15).

\section{DISCUSSION}

The topic of our study corresponds with an ongoing interest in increasing occurrence of respiratory diseases in Eastern Europe (9-12). Epidemiological assessment of the prevalence of paediatric asthma is usually based on the data provided by questionnaire surveys frequently performed within multicentre international projects $(2,13)$. As a result epidemiological estimation of asthma occurrence depends on already known diagnoses made in the past by various physicians. Even if diagnostic guidelines are more and more utilized in clinical practice asthma can be difficult to diagnose in adults but the diagnosis of asthma in children proves to be more difficult because the classic symptoms may not be present in many of affected children $(14,15)$. This is why epidemiological assessment of asthma prevalence is likely to be affected by varying severity and phenotypic expression of the disease in the examined population. Both factors, severity and phenotype, seem to play an important role in epidemiological setting especially that allergic asthma is the most common asthma phenotype (16). In our study we aimed at verification of that view. The goal was to examine the association of already known diagnosis of asthma with asthma-like symptoms and non-respiratory allergic symptoms in a population of school children in the Batumi region. Moreover except for eczema all allergic symptoms and diseases were more prevalent in children with known asthma than in children without asthma. A pertinent observation is provided by the assessment of risk by means of odds ratios. Analysis of questionnaire-derived data showed that the probability of having diagnosed asthma increases in children who have coexisting allergic disorders and respiratory symptoms. Moreover, the largest probability of having diagnosed asthma was found in children who had respiratory symptoms with coexisting any allergic symptom and allergic disease: $\mathrm{OR}=27.02(95 \% \mathrm{CI}$ : 18.18-40.15). The associations reflected by the measurement of odds ratios reflect an exposure-effect pattern.

In our recent paper we reported a $65 \%$ underdiagnosis of paediatric asthma in children residing in the Batumi region and ascribed that phenomenon to age, coexisting allergic disorders and a family history (4). This analysis confirms not only the impact of allergic disorders but also of respiratory status of children as expressed by asthmatic tendency. Moreover, this analysis provides statistical measures of the impact and shows the clear interaction of respiratory symptoms and allergic disorders. These findings may suggest that in the region of our study paediatricians are prudent in arriving at the final diagnosis of asthma, rather tend to avoid early diagnostic decisions and are more likely to make a firm diagnosis when the clinical manifestation is evident, especially in the case of allergic asthma. Such an interpretation supports a published evidence showing that children with fewer respiratory symptoms, with less severe presentation, or without the usual allergic co-morbidities are more likely to be undiagnosed (8). Whether or not the suspected diagnostic practice in the studied region affects management of paediatric asthma at various stages including its early, mild presentation remains to be investigated by separate studies.

\section{CONCLUSIONS}

Relatively low prevalence of paediatric asthma in the Batumi region, Georgia, as assessed by the epidemiological survey reflects an underdiagnosis of the disease. The underestimation of the prevalence of paediatric asthma may result from a number of factors including diagnostic practices of consulting paediatricians. As a result questionnaire-based studies on asthma seem to more readily identify cases in children with more severe clinical presentation of the disease and with coexisting allergic disorders.

\section{Conflict of Interests}

None declared

\section{Acknowledgement}

The study was funded by intramural Medical University of Silesia grant (KNW-1-154/K/9/0) and performed within the bilateral international collaboration between Batumi Shota Rustaveli State University, Georgia, and Medical University of Silesia, Poland.

\section{REFERENCES}

1. Aaron SD, Boulet LP, Reddel HL, Gershon AS. Underdiagnosis and overdiagnosis of asthma. Am J Resp Crit Care Med. 2018;198(8):1012-20.

2. Brożek G, Lawson J, Shpakou A, Fedortsiv O, Hryshchuk L, Rennie D, et al. Childhood asthma prevalence and risk factors in three Eastern European countries - the Belarus, Ukraine, Poland Asthma Study (BUPAS): an international prevalence study. BMC Pulm Med. 2016;16:11. doi: 10.1186/s12890-016-0172-x.

3. Beridze V, Abuladze L, Partenadze N, Bakhtadze T, Lawson J, Zejda JE. Childhood asthma in Batumi, Georgia: prevalence and environmental correlates. J Asthma. 2018;55(1):43-9.

4. Zejda JE, Beridze V, Bakhtadze T, Beridze S, Abuladze L, Partenadze $\mathrm{N}$, et al. Prevalence of and factors associated with underdiagnosis of pediatric asthma in Batumi, Georgia. Allergol Immunopathol (Madr). 2020;48(1):73-7.

5. Baldacci S, Maio S, Simoni M, Cerrai S, Sarno G, Silvi P, et al. The ARGA study with general practitioners: impact of medical education on asthma/rhinitis management. Respir Med. 2012;106(6):777-85.

6. Annesi-Maesano I, Sterlin C, Caillaud D, de Blay F, Lavaud F, Charpin D, et al. Factors related to under-diagnosis and under-treatment of childhood asthma in metropolitan France. Multidiscip Respir Med. 2012;7(1):24. doi: 10.1186/2049-6958-7-24.

7. Zejda JE, Farnik M, Smółka I, Lawson J, Brożek G. Socio-demographic factors related to under-diagnosis of childhood asthma in Upper Silesia, Poland. Ann Agric Environ Med. 2017;24(2):171-5. 
8. Gerald JK, Sun Y, Grad R, Gerald LB. Asthma morbidity among children evaluated by asthma case detection. Pediatrics. 2009;124(5):e927-33.

9. Richter J, Kral V, Rajnohova Dobiasova L, Svozil V, Pohunek P, Vetvicka V. Prevalence of Asthma Bronchiale in the Czech Republic and its economic burden. Am J Immunol. 2016;12(3):61-68.

10. Skrzypek M, Kowalska M, Kobza J, Wypych A, Czech EM, Niewiadomska E, et al. Community-based survey as a basis for evidence-based public health: children living in Upper Silesian Industrial Zone. Cent Eur J Public Health. 2018;26(3):171-6.

11. Brożek G, Lawson J, Szumilas D, Zejda J. Increasing prevalence of asthma, respiratory symptoms, and allergic diseases: Four repeated surveys from 1993-2014. Respir Med. 2015;109(8):982-90.

12. Brożek G, Shpakou A, Lawson J, Zejda J. Rural dwelling and temporal trends in relation to childhood asthma and related conditions in Belarus: a repeated cross-sectional survey. J Agromedicine. 2015;20(3):332-40.
13. Lai CK, Beasley R, Crane J, Foliaki S, Shah J, Weiland S. Global variation in the prevalence and severity of asthma symptoms: phase three of the International Study of Asthma and Allergies in Childhood (ISAAC). Thorax. 2009;64(6):476-83.

14. Massoth L, Anderson C, McKinney KA. Asthma and chronic rhinosinusitis: diagnosis and medical management. Med Sci (Basel). 2019;7(4):53. doi: 10.3390/medsci7040053.

15. Tarasidis GS, Wilson KF. Diagnosis of asthma: clinical assessment. Int Forum Allergy Rhinol. 2015;5 Suppl 1:S23-6.

16. Schatz M, Rosenwasser L. The allergic asthma phenotype. J Aller Clin Immunol Pract. 2014;2(6):645-8.

Received February 5, 2020 Accepted in revised form January 4, 2021 